\title{
VIBRATIONS PIEZO-CONTROL OF FGM BEAM IN A THERMAL ENVIRONMENT
}

\author{
K. EL HARTI ${ }^{1}$, MED. RAHMOUNE ${ }^{2}$, M. SANBI $^{3}$, R. SAADANI ${ }^{1}$, M. BENTALEB ${ }^{1}$, \\ M. RAHMOUNE ${ }^{1}$ \\ 1. laboratoire d'étude des matériaux avancés et applications, EST-FS, University of Moulay Ismail, \\ Meknès \\ 2. National School of Applied Sciences, University of Mohammed First, Oujda \\ 3. National School of Applied Sciences, University of Abdelmalek Essaadi, Tétouan \\ Auteur correspondant: elhartikhalid@gmail.com
}

\begin{abstract}
An analytical method on the active vibration control of a functionally graded beam equipped with layers of piezoelectric sensors and actuators, in a thermal environment, is studied. The study based on EulerBernoulli theory and finite element method, applied to a flexible beam divided into a finite number of elements. The equations of motion are obtained by applying the principle of Hamilton. The structure is modeled analytically then numerically and the results of the simulations are presented to visualize the states of their dynamics.
\end{abstract}

\section{Résumé}

Une méthode analytique sur le contrôle actif des vibrations d'une poutre en matériau à gradient fonctionnelle équipée par des couches de matériau piézoélectrique, utilisées comme capteurs et actionneurs, dans un environnement thermique, est étudiée. Basé sur la théorie d'Euler-Bernoulli et de la méthode des éléments finis, appliquée à une poutre flexible divisée en un nombre fini d'éléments. Les équations de mouvement sont obtenues en appliquant le principe de Hamilton. La structure est modélisée analytiquement puis numériquement et les résultats des simulations sont présentés afin de visualiser les états de leur dynamique.

Mots clefs : Matériaux FGM, piézoélectricité, EulerBernoulli, contrôle LQG-Kalman.

Keywords : FGM materials, piezoelectricity, EulerBernoulli, LQG Control-Kalman.

\section{Introduction}

Improving the performance of the structural parts can lead to finding, in the same material, different properties, often antagonistic, but optimized at the local level. The development of composite materials has made it possible to combine the specific properties of different materials in the same piece. FGM materials can be produced by modifying, continuously, the components of materials in a predetermined profile. The most distinct features of FGM materials are their non-uniform microstructures with spatially graded macros properties. It is designed to improve and optimize the thermo-electro-mechanical characteristics of structures at the micro and nano scale [1]. Most FGM families are progressively composed of metal-refractory ceramics. Generally, FGMs are constructed from a mixture of ceramic and metal or a combination of different materials. Ceramic in a FGM provides a barrier against thermal effects and at the same time protects the metal against corrosion and oxidation, and the material is hard and reinforced by the metal composition. Currently, FGMs are developed for general use as structural elements in extremely high temperature environments and for different applications. Due to the wide application of FGM, several investigations have been carried out on the mechanical and thermal behavior of the material. [2], [3]. Theoretical and experimental studies have been carried out and published on fracture mechanics [4], on the distribution of thermal stresses [5], [6], and on treatment etc. Among these structures, the beams have always remained the interest of researchers because of their applications. The objective of this work is to analyze the vibratory behavior of a multilayer beam in a thermal environment, using the finite element method, then the active control via the piezoelectric elements PZT.

\section{Mathematical model}

Consider a beam of dimension $(L \times b \times t)$ in the directions $(x, y, z)$ as shown in Figure 1. The beam consists of FGM material metal compounds and ceramics, partially covered by piezoelectric actuators and sensors bonded to the upper and lower faces of FGM. The structure has a geometrics' and material's symmetry with respect to its neutral plane, the mechanical part is then similar to that of a homogeneous beam in sections, where there is a decoupling between traction and bending, the curvature of the beam only produces a bending moment [7]. We therefore place ourselves in a case of pure flexion.

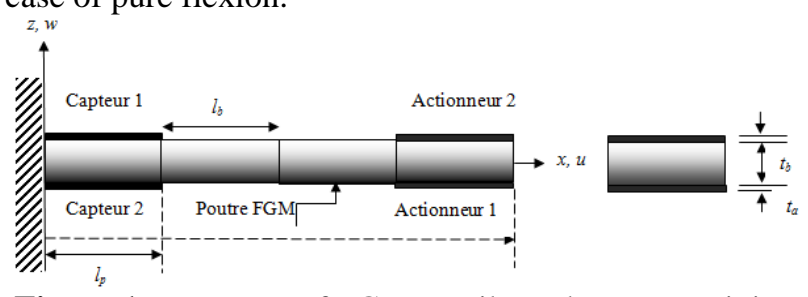

Figure 1: geometry of FGM cantilever beam containing piezoelectric layers.

In this study, the power law is considered to describe the variation of material properties from the pure metal to the lower face $\mathrm{z}=-\mathrm{h} / 2$ up to pure ceramic at the top face $\mathrm{z}=+\mathrm{h} / 2$ of the beam. 


$$
V_{c}=\left(\frac{z}{h}\right)^{k}=1-V_{m}
$$

Where $V_{c}$ and $V_{m}$ are the volume fractions of the ceramic and metallic constituents respectively and $k$ is the exponent of the volume fraction which dictates the material's variation profile across the thickness of the beam.

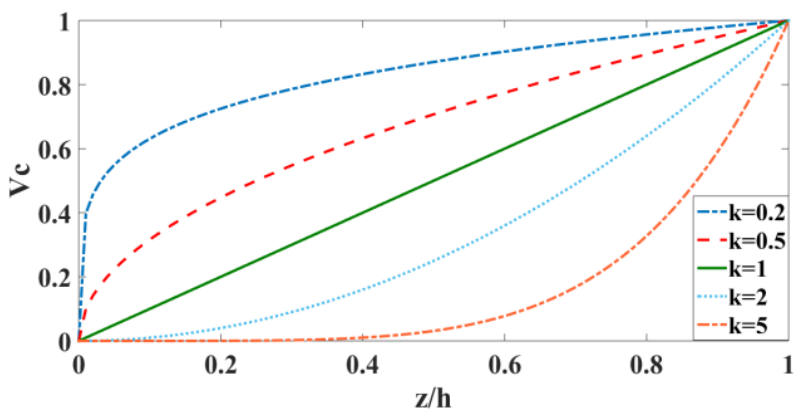

Figure 2: Variation of the volume fraction according to the thickness.

Therefore, the material properties of the beam, ie the Young's modulus $E$ and the mass density $\rho$, vary continuously in the direction of the thickness.

$$
\begin{aligned}
& \mathrm{E}(\mathrm{z})=\mathrm{E}_{\mathrm{m}}+\left(\mathrm{E}_{\mathrm{c}}-\mathrm{E}_{\mathrm{m}}\right)\left(\frac{\mathrm{z}}{\mathrm{h}}\right)^{\mathrm{k}} \\
& \rho(z)=\rho_{m}+\left(\rho_{c}-\rho_{m}\right)\left(\frac{z}{h}\right)^{k}
\end{aligned}
$$

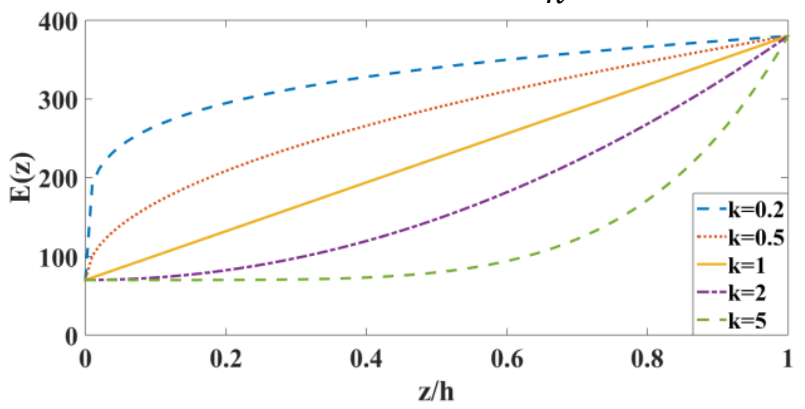

Figure 3: Variation of Young's modulus according to the thickness.

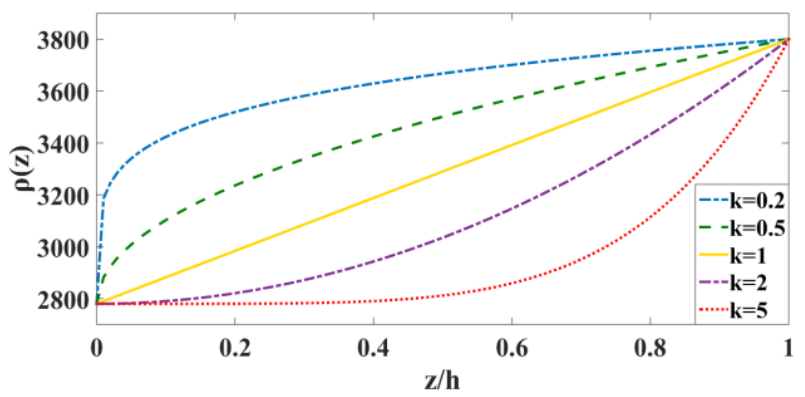

Figure 4: Variation of the density according to the thickness.

Where the indices $m$ and $c$ designate respectively the constituents, metal and ceramic.

Considering the Euler-Bernoulli beams theory, the axial and transverse displacements, $u$ and $w$, of any point of the beam are given by:

$$
\begin{gathered}
u(x, y, z, t)=z \frac{\partial w(x, t)}{\partial x} \quad v(x, y, z, t)=0 \\
w(x, y, z, t)=w(x, t)
\end{gathered}
$$

The stress and strain components corresponding to this displacement field are given by:

$$
\begin{gathered}
\varepsilon_{x x}=\frac{\partial u}{\partial x}=z \frac{\partial^{2} w(x, t)}{\partial x^{2}} \\
\sigma_{x x}=E z \frac{\partial^{2} w(x, t)}{\partial x^{2}}
\end{gathered}
$$

The application of the generalized Hamilton principle gives:

$$
\delta \int_{t_{1}}^{t_{2}}(U-T+W) d t=0
$$

The deformation energy of the system $(U)$ can be expressed as follows:

$$
U=\frac{1}{2} \iiint_{V}\left(\sigma_{x x} \varepsilon_{x x}\right) d V=\frac{1}{2} \iiint_{V} E z^{2}\left(\frac{\partial^{2} w}{\partial x^{2}}\right)^{2} d V
$$

The kinetic energy of the system $(T)$ is given by:

$$
T=\frac{1}{2} \iiint_{V} \rho\left(\frac{\partial w}{\partial t}\right)^{2} d V=\frac{1}{2} \int_{0}^{l} \iint_{A} \rho\left(\frac{\partial w}{\partial t}\right)^{2} d A d x
$$

The work done by the distributed transverse force $f(x, t)$ is given by:

$$
W=\int_{0}^{l} f w d x
$$

Dynamics due to the deformation behavior of the embedded-free element is governed by the following four-order differential equation:

$$
\frac{\partial^{2}}{\partial x^{2}}\left(E I \frac{\partial^{2} w(x, t)}{\partial x^{2}}\right)+\rho A \frac{\partial^{2} w(x, t)}{\partial t^{2}}=f_{\text {ext }}
$$

The solution of the equation is supposed to have a cubic form according to $x$ and is written:

$$
w(x, t)=a_{1}+a_{2} x+a_{3} x^{2}+a_{4} x^{3}
$$

Based on the Euler-Bernoulli hypotheses, and using boundary conditions for two degrees of freedom per node, the final form of $w(x, t)$ becomes:

$$
\begin{gathered}
{[(w(x, t)]=} \\
{\left[\begin{array}{lllll}
f_{1}(x) & f_{2}(x) & f_{3}(x) & f_{4}(x)
\end{array}\right]\left[\begin{array}{llll}
w_{1} & \theta_{1} & w_{2} & \theta_{2}
\end{array}\right]^{T}} \\
=\left[n^{T}\right][q]
\end{gathered}
$$

With

$$
\begin{gathered}
{\left[\left(\dot{w}^{\prime}(x, t)\right]=\left[n_{2}^{T}\right][q]\right.} \\
{\left[\left(w^{\prime \prime}(x, t)\right]=\left[n_{1}^{T}\right][q]\right.} \\
{[\dot{w}(x, t)]=\left[n_{3}^{T}\right][\dot{q}]}
\end{gathered}
$$

The equation of motion of the two-node element is obtained by replacing equations (8) and (9) in the following Lagrange equation:

$$
\frac{d}{d t}\left[\frac{\partial T}{\partial \dot{q}_{i}}\right]+\left[\frac{\partial U}{\partial q_{i}}\right]=\left[Z_{i}\right]
$$

The equation (17) becomes:

$$
M \ddot{q}+K q=f(t)
$$

\section{Dynamic equation and state space model} In order to be interested in controlling the first modes of vibration, we used the transformation $q=T g$, with $T$ 
being the modal matrix and $g$ the principal coordinates. Consider the following Rayleigh proportional damping:

$$
C=\alpha M+\beta K
$$

The structure dynamics equation and the control equation are presented by:

$$
\begin{gathered}
M^{*} \ddot{g}+C^{*} \dot{g}+K^{*} g=f_{e x t}^{*}+f_{c t r 1}^{*}+f_{c t r 2}^{*}+f_{t h}^{*} \\
y(t)=V^{S}(t)=p^{T} T \dot{g}
\end{gathered}
$$

The state space model in MIMO mode of the beam, for first vibratory mode is given by:

$$
\begin{gathered}
\dot{x}=A x(t)+B u(t)+E r(t)+E^{t h} \\
y(t)=C^{T} x(t)+D u(t)
\end{gathered}
$$

\section{Results and discussion}

In order to validate the control procedure, we consider a flexible beam embedded at its left end, made of the FGM material and partially covered by layers of the piezoelectric material. Table1 presents the geometric and physical characteristics of the different materials.

\begin{tabular}{|c|c|c|}
\hline $\begin{array}{c}\text { Physical } \\
\text { properties }\end{array}$ & FGM & $\begin{array}{c}\text { PZT } \\
\text { Sen./Act. }\end{array}$ \\
\hline Length $(\mathrm{m})$ & $L_{b}=0.25$ & $L_{c}=L_{a}=0.25 / 4$ \\
\hline Width $(\mathrm{m})$ & $b=0.03$ & $b_{c}=b_{a}=0.03$ \\
\hline Thickness $(\mathrm{m})$ & $h=0.002$ & $h_{c}=h_{a}=10^{-5}$ \\
\hline Density $\left(\mathrm{Kg} / \mathrm{m}^{3}\right)$ & $\begin{array}{c}\rho_{m}=2780 \\
\rho_{c}=3800\end{array}$ & $\rho_{p}=7700$ \\
\hline $\begin{array}{c}\text { Young's } \\
\text { modulus }(G \mathrm{~Pa})\end{array}$ & $\begin{array}{c}E_{m}=70 \\
E_{c}=380\end{array}$ & $E_{p}=68.1$ \\
\hline $\begin{array}{c}\text { PZT strain } \\
\text { constant }(\mathrm{m} / \mathrm{V})\end{array}$ & - & $d_{31}=1.2510^{-12}$ \\
\hline $\begin{array}{c}\text { PZT stress } \\
\text { constant }(\mathrm{Vm} / \mathrm{N})\end{array}$ & - & $g_{31}=10.510^{-3}$ \\
\hline
\end{tabular}

Tableau 1: Physical and geometrical properties of FGM and piezoelectric materials.

The beam is subjected to an external force in the form of an amplitude pulse $(1 \mathrm{~N})$ applied for a duration of one second at the free end of each model. In this study, we were interested only in the first mode of vibration.

The figures below show the impulse response of the beam. In all the results, we compare controlled and uncontrolled responses.

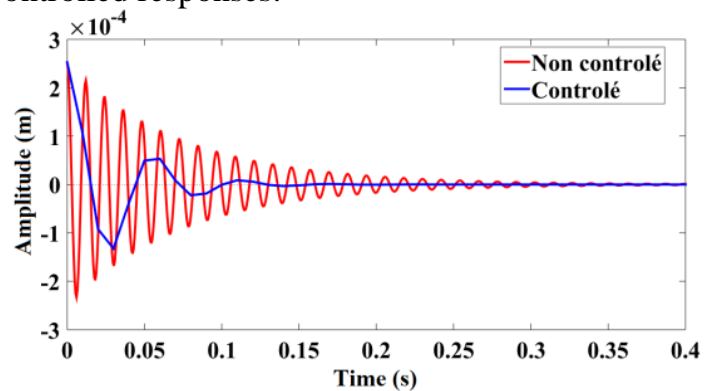

Figure 5 : Impulse response of the beam

$\left(k=0.5 ; Q=10^{7} ; R=1 ; R_{c}=100\right)$

To introduce the temperature effect, it is assumed that the upper surface of the beam is heated. Figure 6 shows the response with application of a thermal gradient of $5^{\circ} \mathrm{C}$. Figure 7 presents a comparison of the vibration frequencies with and without consideration of the heat flux, keeping the position of the sensors in FE1 and the actuators vary between FE2 and FE4.

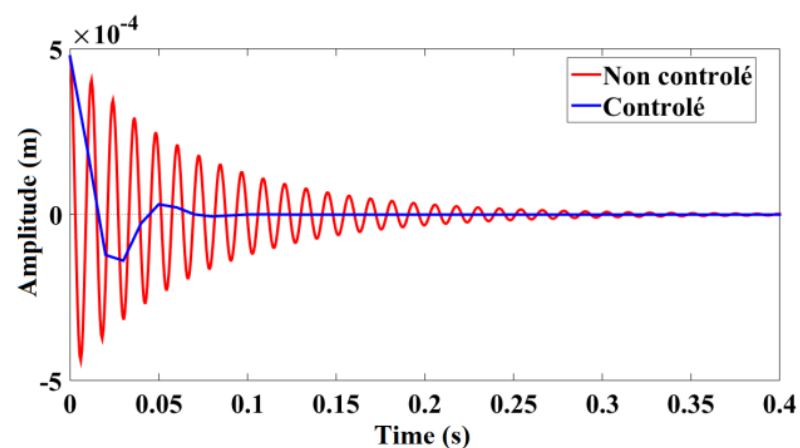

Figure 6: Impulse response of the beam by applying the thermal effect

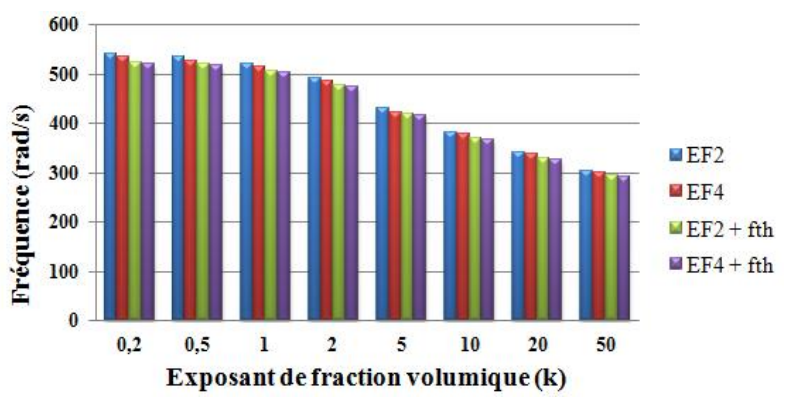

Figure 7: Variation of vibration frequency as a function of the volume fraction exponent

\section{Conclusion}

Theoretical analysis of vibration and its active control of an intelligent beam in a thermal environment is studied. We have also shown that the implementation of the vibration control of the structure, taking into account the thermal effect, does not diminish the quality of the control, which confirms the reliability of our optimal control procedure LQG accompanied by the Kalman filter .

\section{Références}

[1] T.K., Quelque méthodes pour l'estimation des propriétés effectives des plaques hétérogène, Thèse, Université de Paris-Est, 2008.

[2] Y. Tanigawa, Some basic thermo-elastic problems for nonhomogeneous structural materials, Applied Mechanics Reviews 48 (1995) 287-300.

[3] S. Suresh, A. Mortensen, Fundamentals of Functionally Graded Materials, IOM Communications, Londres Angleterre 1998.

[4] P. R. Marur, Fracture Behaviour of Functionally Graded Materials, Thèse, Université d' Auburn, Alabama, 1999.

[5] R. L. Williamson, B. H. Rabin, J. T. Drake, Finite element analyses of thermal residual stresses at graded ceramic-metal interfaces-part I: model description and geometrical effects, Journal of Applied Physics, 74(2) (1995) 1310-1320.

[6] N. Naotake, Thermal stresses in functionally graded materials, Journal of Thermal Stresses, 22(4-5) (1999) 477-512.

[7] J. Ducarne, Modélisation et optimisation de dispositifs non-linéaire d'amortissement de structures par systèmes piézoélectriques commutés, Thèse, LMSSC, Cnam Paris 2009. 